\title{
Targeting aminopeptidase N, a newly identified receptor for F4ac fimbriae, enhances the intestinal mucosal immune response
}

\author{
V Melkebeek ${ }^{1,5}$, K Rasschaert ${ }^{1,5}$, P Bellot ${ }^{1,5}$, K Tilleman $^{2}$, H Favoreel $^{1}$, D Deforce ${ }^{2}$, BG De Geest ${ }^{3}$, \\ BM Goddeeris ${ }^{1,4}$ and $\mathrm{E}$ Cox $^{1}$
}

Enterotoxigenic Escherichia coli (ETEC) are a major cause of diarrhea in human and animal. In piglets, ETEC having F4 fimbriae (F4+ ETEC) induce severe diarrhea, dependent on the presence of receptors for F4 (F4R). In this study, porcine aminopeptidase $N(P A P N)$ was identified as an F4R by comparative proteomic analysis of brush border proteins of F4R ${ }^{+}$ and F4R- pigs and by adherence/internalization experiments on PAPN-transfected cells. Binding of F4 fimbriae to pAPN depended on sialic acid containing carbohydrate moieties, and resulted in clathrin-mediated endocytosis of the fimbriae. Endocytosis via pAPN was not restricted to F4 fimbriae, but was also observed for anti-pAPN antibodies. Both F4 fimbriae- and pAPN-specific antibodies were taken up in vivo by porcine enterocytes and induced subsequently a rapid immunoglobulin $A$ and $G$ response. In conclusion, we identified pAPN as an endocytotic receptor for F4 fimbriae and highlight the opportunity to target vaccine antigens to this epithelial receptor.

\section{INTRODUCTION}

Enterotoxigenic Escherichia coli (ETEC) are an important cause of diarrhea in man and animal. ETEC infections are the leading cause of travellers' diarrhea and a major cause of diarrhea in developing nations, where it can be life-threatening among children. ${ }^{1,2}$ Porcine ETEC isolates express, respectively, five different types of fimbriae: F4, F5, F6, F18, and F41 of which F4 is most abundant and involved in neonatal and postweaning diarrhea. ${ }^{3,4}$ Three antigenic variants of F4 have been identified, namely F4ab, F4ac, and F4ad, of which F4ac is the most common type.

$\mathrm{F}^{+}$ETEC adhesion is mediated by specific receptors (F4R) expressed on the brush border of small intestinal enterocytes and is dominantly inherited. ${ }^{5}$ Interestingly, oral immunization of pigs with soluble F4ac fimbriae induces a protective immune response against challenge with $\mathrm{F} 4 \mathrm{ac}^{+}$ETEC. ${ }^{6}$ Moreover, oral immunization with F4ac-coupled human serum albumin has demonstrated that F4ac has the potential to serve as a carrier molecule to induce mucosal immune responses against coupled antigens. ${ }^{7}$ Orally administered F4ac is transcytosed by $M$ cells and follicle-associated enterocytes in the Peyers' patches and by villous enterocytes in the lamina propria. ${ }^{8}$ Subsequent uptake and presentation of F4ac by antigen-presenting cells could explain its capacity to induce a mucosal immune response. ${ }^{8}$ This implies that targeting selected antigens to one or more of the F4ac receptors (F4acRs) may have the potential to elicit efficient mucosal immune responses against these antigens. Also intestinal mucin-type glycoprotein 1 and 2 have been identified as receptors for F4ac, $, 9,10$ but these have not been reported to initiate endocytosis or induction of a mucosal immune response, and are therefore unlikely to be F4acRs involved in transcytosis and induction of mucosal immunity.

The aim of this study was to identify an F4 receptor in epithelial brush borders that mediates endocytosis of F4 fimbriae and is involved in its mucosal immunogenicity.

\section{RESULTS}

Identification of aminopeptidase $\mathrm{N}$ as a potential F4ac receptor (F4acR)

To identify an F4acR, brush border membrane vesicles (BBMV) from $8 \mathrm{~F}_{4} \mathrm{acR}^{+}$and $5 \mathrm{~F}_{4} \mathrm{acR}^{-}$pigs were separated in duplo by

\footnotetext{
${ }^{1}$ Laboratory of Immunology, Faculty of Veterinary Medicine, Ghent University, Merelbeke, Belgium. ${ }^{2}$ Laboratory of Pharmaceutical Biotechnology, Ghent University, Ghent, Belgium. ${ }^{3}$ Laboratory of Pharmaceutical Technology, Ghent University, Ghent, Belgium. ${ }^{\circ}$ Department of Biosystems, Faculty of Bioscience Engineering, KULeuven, Leuven, Belgium. ${ }^{5}$ These authors equally contributed to this work. Correspondence: V Melkebeek (Vesna.Melkebeek@ugent.be) 

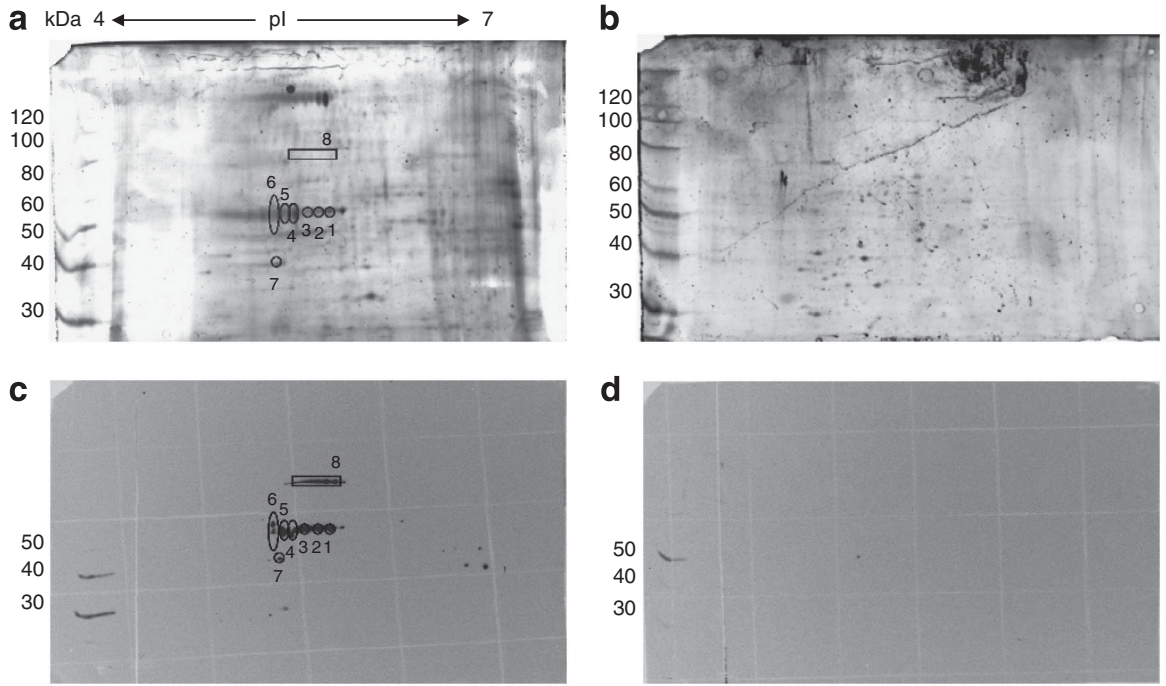

Figure 1 Identification of aminopeptidase $\mathrm{N}$ as a potential F4ac receptor. Brush border membrane vesicles from an F4 receptor (F4R) ${ }^{+}(\mathbf{a}, \mathbf{c})$ and F4R- (b, d) pig were separated via two-dimensional electrophoresis and stained with Sypro Ruby to visualize the proteins (a, b) or used for immunoblotting to visualize proteins that specifically bind F4ac (c, d). Eight protein spots were reproducibly detected among the $\mathrm{F}_{4} \mathrm{R}^{+}$pigs and were absent in the $5 \mathrm{~F}_{4} \mathrm{R}^{-}$pigs. Mass spectrometric analysis allowed the identification of aminopeptidase $\mathrm{N}$ in spot 4,5 , and 6 with high confidence.

two-dimensional electrophoresis. One gel was stained with Sypro Ruby for total protein while the other gel was immunoblotted with F4ac to identify F4ac-binding proteins. Protein spots from the Sypro Ruby stained gel, which aligned to spots on the western blot were excised from the gel.

Eight spots were reproducibly detected among the eight $\mathrm{F} 4 \mathrm{R}^{+}$ pigs and were absent in the five $\mathrm{F}^{-} \mathrm{R}^{-}$pigs (Figure 1). After tryptic digestion, followed by nano-liquid chromatography-Q-timeof-flight mass spectrometry analysis (Table $\mathbf{1}$ ), aminopeptidase $\mathrm{N}$ was identified with high confidence in spot 4,5 , and 6 . The only detectable protein in the (weak) spots 7 and 8 was trypsin, which had been used during in-gel proteolytic digestion. The other spots contained proteins that could be excluded as F4acR, like ubiquinol cytochrome $\mathrm{C}$ reductase (spots 1 and 2), an enzyme of the mitochondrial respiratory chain, and hemoglobin (spot 3) of red blood cells. Based on these data, porcine aminopeptidase $\mathrm{N}$ (pAPN) was further examined as a candidate receptor for F4ac fimbriae.

\section{APN promotes internalization of $F 4 a c$ fimbriae through clathrin-mediated endocytosis}

To address the putative receptor role of APN in mediating internalization of F4ac fimbriae, pAPN-transfected BHK-21 cells and FLUOS-labeled F4 were used. F4 bound specifically to pAPN-transfected BHK-21, whereas no binding could be observed on untransfected BHK-21 cells. Upon binding, FLUOS-labeled F4 was internalized in pAPN-transfected BHK21 (data not shown). To determine the endocytotic pathway of F4 internalization in pAPN-transfected BHK-21 cells, inhibitors of phagocytosis (dynamin inhibitory peptide), of clathrin-mediated endocytosis (amantadine- $\mathrm{HCl}$ and hypertonic sucrose) and of caveolae-mediated endocytosis (nystatin), an actin disrupting agent (latrunculin B), an inhibitor that blocks
G/F-actin polymerization and budding of clathrin-coated vesicles (cytochalasin D) and the APN-specific inhibitor, bestatin, were used. The concentrations of inhibitors used in these experiments caused no significant decrease in cell viability as analyzed by flow cytometry with propidium iodide (data not shown).

Bestatin substantially reduced FLUOS-labeled F4 internalization in a dose-dependent manner, supporting the importance of pAPN during internalization. Hypertonic sucrose, amantadine, dynamin inhibitory peptide, and cytochalasin $\mathrm{D}$ also reduced the internalization of F4 fimbriae in PAPN-BHK cells in a dosedependent manner, while both latrunculin $B$ and nystatin had no effect (Figure 2).

To confirm the involvement of clathrin in endocytosis of $\mathrm{F} 4$, double immunofluorescence stainings for F4ac and clathrin were performed on pAPN-BHK cells. A clear colocalization between F4ac and clathrin could be observed during F4 invagination from the plasma membrane (Figure 3). Vesicles that were completely internalized in the cytoplasm no longer colocalized with clathrin, indicating their release of clathrin coat.

\section{Binding of F4ac to its receptor is dependent on carbohydrate moieties}

Previous studies have demonstrated that binding of F4 fimbriae to the intestinal epithelium is dependent on the presence of particular carbohydrates. To confirm this and to characterize these carbohydrates, BBMVs from $\mathrm{F} 4 \mathrm{R}^{+}$pigs were treated with several chemicals or enzymes to identify specific carbohydrates involved in binding of F4 fimbriae to their receptor. Treatment of BBMVs with $25 \mathrm{mM} \mathrm{NaIO}_{4}$ for 30 min substantially reduced binding of F4 fimbriae, whereas treatment for $2 \mathrm{~h}$ completely abolished binding (Figure 4). 
Table 1 Mass spectrometric analysis

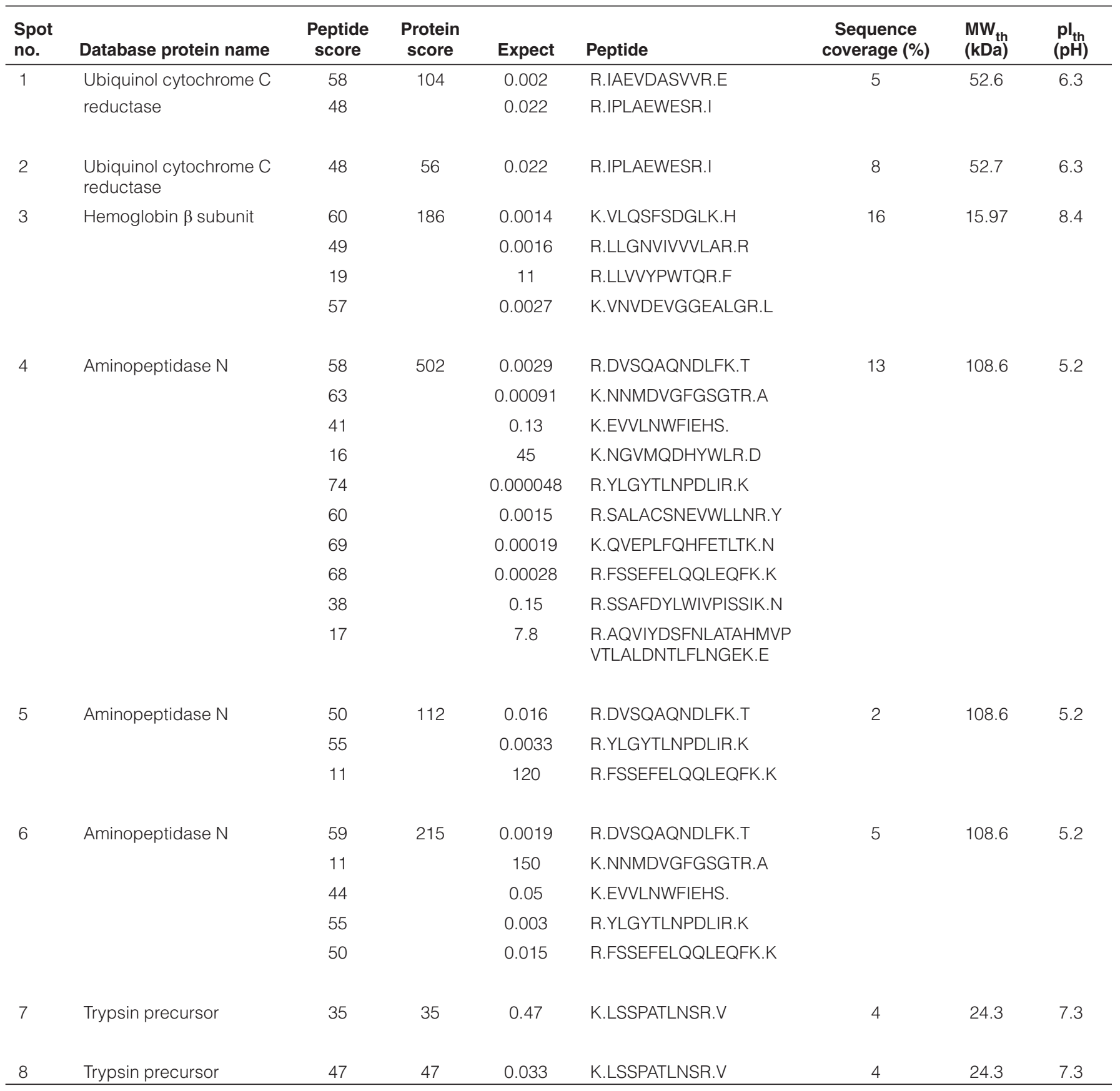

Spot no., these numbers refer to Figure 3; the peptide score, the ion score for the individual peptide; the protein score, probability Mowse score reported by matrix science where $P<0.05$ of the individual ions scores indicates identity or extensive homology; expect, the expectation value for the peptide match (the lower this value, the more significant the result); peptide, the sequence of the peptide; MWth, molecular weight of the protein spot obtained theoretically from the Swiss-Prot database (http://www.expasy.org); plth, isoelectric point of the protein spot obtained theoretically from the Swiss-Prot database (http://www.expasy.org).

Treatment of BBMVs with recombinant neuraminidase from Arthrobacter urefaciens, removing $\alpha 2-3,6,8,9$-linked sialic acid, also resulted in a reduction in binding of $\mathrm{F} 4$ fimbriae, suggesting that sialic acids are involved in F4R binding (Figure 5).

Subsequently, BBMVs were treated with $\mathrm{N}$-glycosidase F that removes all $\mathrm{N}$-glycans, or with endoglycosidase $\mathrm{H}$ that removes only high mannose $\mathrm{N}$-glycans. $\mathrm{N}$-glycosidase F treat- ment reduced $\mathrm{F} 4$ binding, whereas endoglycosidase $\mathrm{H}$ did not (Figure 5b).

\section{APN as a target for oral vaccine delivery}

To further address the ability of APN to induce endocytosis, and to assess APN-mediated endocytosis in vivo and its potential ability to elicit an immune response, polyclonal rabbit 

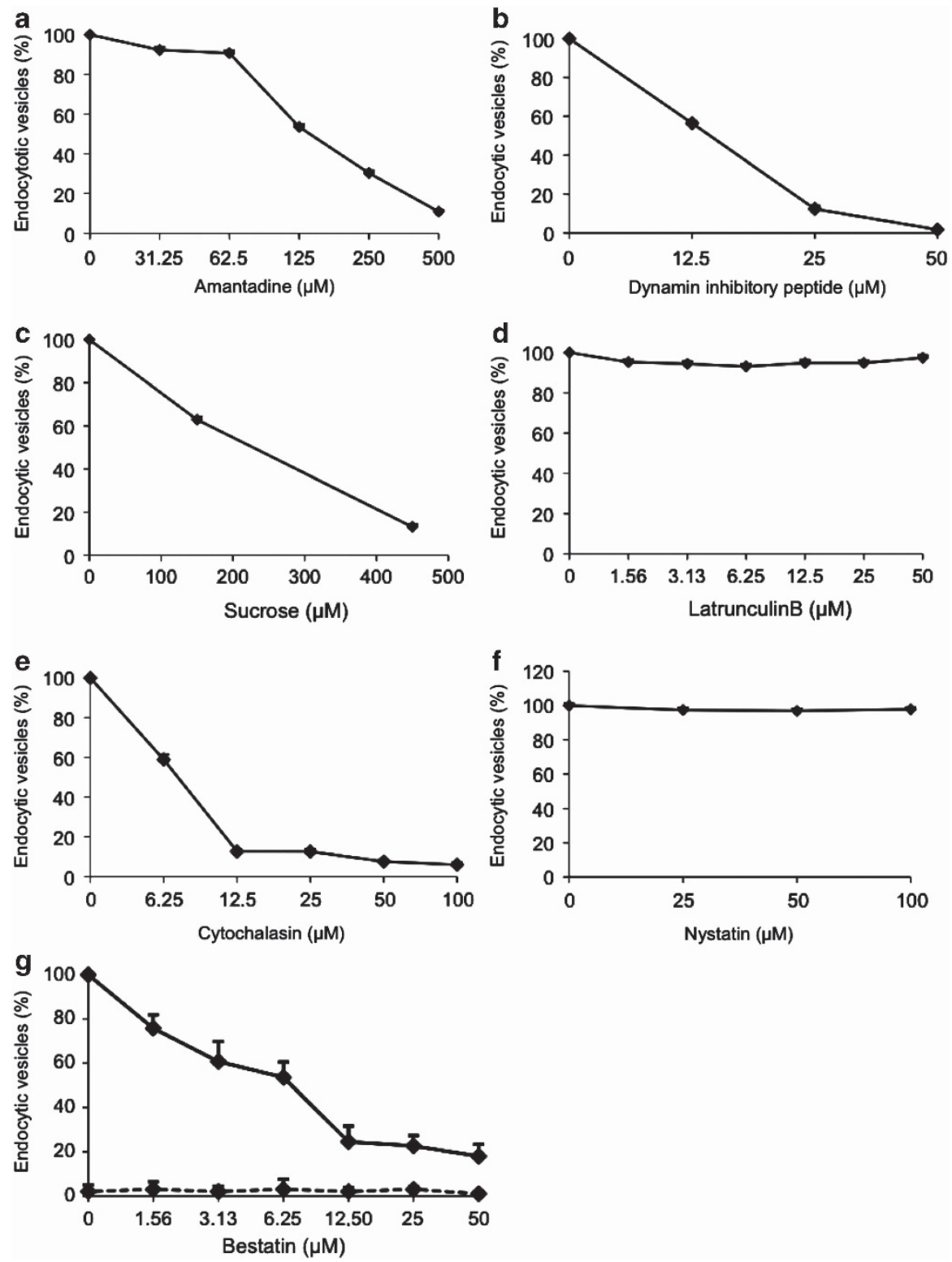

Figure 2 Effect of different inhibitors on the internalization of F4-FLUOS by porcine aminopeptidase N (pAPN)-transfected BHK-21 (solid line) and BHK-21 cells (dotted line). Cells were incubated with F4-FLUOS in the presence of different concentrations of (a) amantadine, (b) dynamin inhibitory peptide, (c) sucrose, which all interfere with clathrin-mediated endocytosis, (d) latrunculin B, which disrupts the actin cytoskeleton, (e) cytochalasin D, which inhibits G-actin polymerization to F-actin and budding of clathrin-coated vesicles, (f) nystatin, which inhibits caveolae-mediated endocytosis, and (g) the APN inhibitor bestatin. The number of internalized vesicles was quantified and expressed as a percentage relative to the number of internalized vesicles in the absence of the inhibitor. Data represent the mean \pm s.d. of three independent experiments.

serum specific for APN was produced as an alternative ligand for APN.

Like F4 fimbriae, polyclonal anti-APN antibodies were bound and were endocytosed in pAPN-transfected BHK-21 cells. These processes were APN-specific as binding to and uptake of antiAPN could not be observed using untransfected BHK-21 cells. As an additional control, irrelevant rabbit serum also did not bind to and was not taken up by pAPN-transfected BHK-21 cells (Figure 6).

Adhesion and endocytosis of polyclonal anti-APN were also evaluated in vivo on cryosections of pig jejunal loops incubated for 5,15 , or $45 \mathrm{~min}$ with anti-APN or with an irrelevant rabbit serum as a control. After $5 \mathrm{~min}$, the anti-APN had bound to the brush border membrane of enterocytes, and could clearly be observed within the enterocytes after 15 and 45 min of incubation. Conversely, no binding of irrelevant rabbit serum occurred after 5 and $15 \mathrm{~min}$, although binding and some uptake could be detected after $45 \mathrm{~min}$ incubation, but to a much lower extent as compared with anti-APN serum (Figure 7).

To determine whether receptor-mediated uptake of anti-APN is followed by the induction of an immune response, a preliminary experiment was performed in pigs. Pigs were orally given anti-APN rabbit immunoglobulin (Ig) G (anti-APN group) or an equal amount of $\operatorname{IgG}$ purified from irrelevant rabbit serum 
a

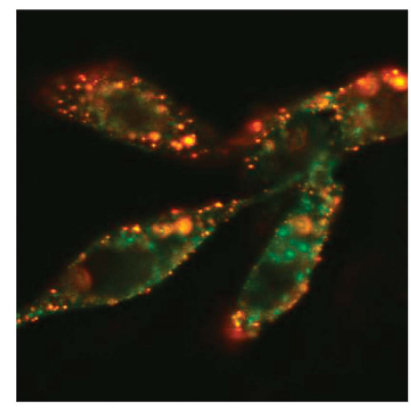

b

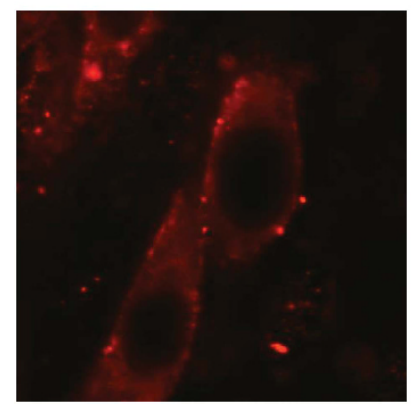

Clathrin
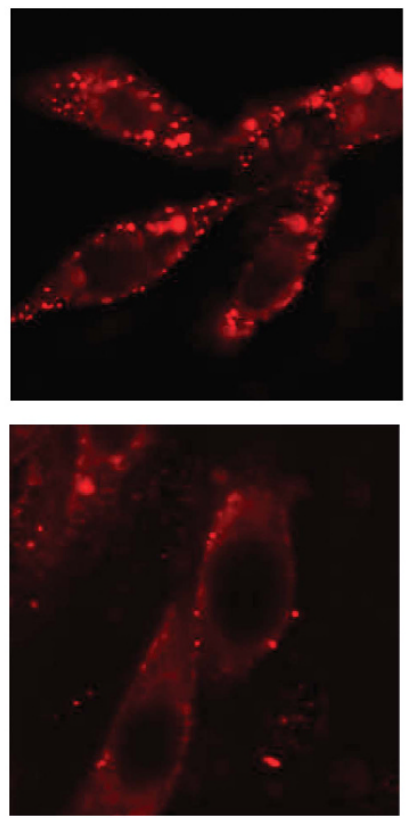

FLUOS-labeled-F4
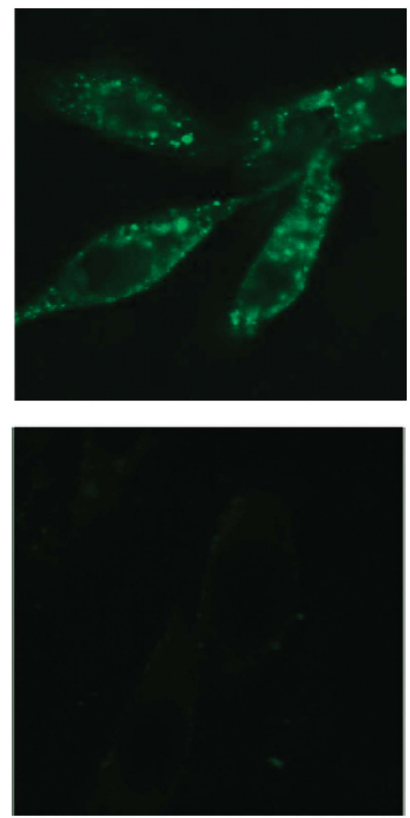

Figure 3 Colocalization of F4-FLUOS with clathrin during endocytosis in porcine aminopeptidase N (pAPN)-transfected BHK-21 cells. F4-FLUOS (green fluorescence) was added to the pAPN-BHK (a) and BHK (b) cells for $30 \mathrm{~min}$ at $37^{\circ} \mathrm{C}$, cells were fixed, permeabilized, and stained as described in materials and methods to detect clathrin (red fluorescence). Images represent a single confocal z-section through the middle of the cell. Arrows indicate the colocalization. Scale bar: $10 \mu \mathrm{m}$.

\begin{tabular}{|c|c|c|c|c|c|c|c|c|c|c|c|}
\hline & \multicolumn{5}{|c|}{$30 \mathrm{~min}$} & \multicolumn{6}{|c|}{$120 \min$} \\
\hline $\mathrm{F} 4 \mathrm{R}^{-}$ & & & & & & $\mathrm{F} 4 \mathrm{R}^{-}$ & & & & & \\
\hline $\mathrm{F} 4 \mathrm{R}^{+}$ & - & - & 。 & & ? & $\mathrm{F}_{4} \mathrm{R}^{+}$ & 。 & 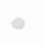 & & & \\
\hline $\mathrm{NaIO}_{4}$ & 0 & 5 & 25 & 50 & 100 & & 0 & 5 & 25 & 50 & 100 \\
\hline
\end{tabular}

Figure 4 Dot-blot analysis of the binding of F4 fimbriae to brush border membrane vesicles (BBMVs) of $\mathrm{F} 4$ receptor $(\mathrm{F} 4 \mathrm{R})^{+}$and $\mathrm{F} \mathrm{R}^{-}$pigs after periodate treatment. The BBMVs of $\mathrm{F}_{4} \mathrm{R}^{+}$and $\mathrm{F} 4 \mathrm{R}^{-}$pigs were treated in solution with different concentrations of $\mathrm{NaIO}_{4}$ ranging from 0 to $100 \mathrm{~mm}$ as shown.

(IgG group), or with anti-APN IgG or IgG from irrelevant rabbit serum adjuvanted with cholera toxin (CT) (anti-APN + CT group and $\operatorname{Ig} \mathrm{G}+\mathrm{CT}$ group, respectively). Although serum IgA, $\operatorname{IgG}$, and IgM directed against rabbit IgG only appeared $13 \mathrm{dppi}$ (days post-primary immunization) in the IgG group, a serum IgG, IgA, and IgM response could be observed as soon as $7 \mathrm{dppi}$ with anti-APN. This response reached a maximum $13 \mathrm{dppi}$ (mean IgG, IgA, IgM titers of 320,113, and 23, respectively, compared with mean IgG, IgA, IgM titers of 44,11 , and 17 , respectively, in the IgG group), and was only slightly boosted by a secondary immunization. Furthermore, the serum antibody response in the IgG group remained lower than in the antiAPN group during the course of the experiment. Addition of $\mathrm{CT}$ (IgG + CT group) increased the IgA, IgG, and IgM response in animals immunized with control IgG to similar titers as observed in the anti-APN group, whereas addition of CT to anti-APN further increased IgA and IgG titers at least threefold from day 13 onwards, resulting in significantly higher IgA and
IgG titers on days 13, 20, and 27 and significantly higher IgM titers on day 20 in the anti-APN + CT group compared with the IgG group. Significant differences between the other groups were not observed (Figure 8).

\section{DISCUSSION}

We have identified pAPN as a novel receptor for F4ac fimbriae. Aminopeptidase $\mathrm{N}$ is a type II membrane glycoprotein belonging to the family of membrane-bound metalloprotease ${ }^{11}$ and is expressed by a variety of cells, including porcine enterocytes. ${ }^{12}$ Some members of group I Coronaviridae (i.e., transmissible gastroenteritis virus, feline infectious peritonitis virus, and human coronavirus (229E)) utilize aminopeptidase $\mathrm{N}$ as a cell surface receptor. ${ }^{13-15}$ Like we show here for F4 fimbriae, transmissible gastroenteritis virus recognizes pAPN expressed on enterocytes in a sialic acid-dependent manner. ${ }^{16}$

The major similarity among brush border receptors that bind fimbrial adhesins is that they all constitute glycoconjugates with a specificity determined by their carbohydrate moiety. Our finding that binding of F4ac to BBMVs depends on glycosylation is in line with earlier reports that binding of F4 fimbriae to the F4R is dependent on the presence of a carbohydrate structure. ${ }^{10}$ Treatment of BBMVs with neuraminidase from A. urefaciens reduced binding of F4, leaving a possible role for $\alpha 2-3,6,8$ sialic acid linkages. Enzymatic removal of all $\mathrm{N}$-linked glycans on the BBMV s using $N$-glycosidase $\mathrm{F}$ also reduced the binding of F4ac, whereas exclusive removal of non-sialylated $N$-linked glycans of the high-mannose type with endoglycosidase- $\mathrm{H}$ had no effect. These results suggest that F4ac is a sialic acid-binding lectin and 

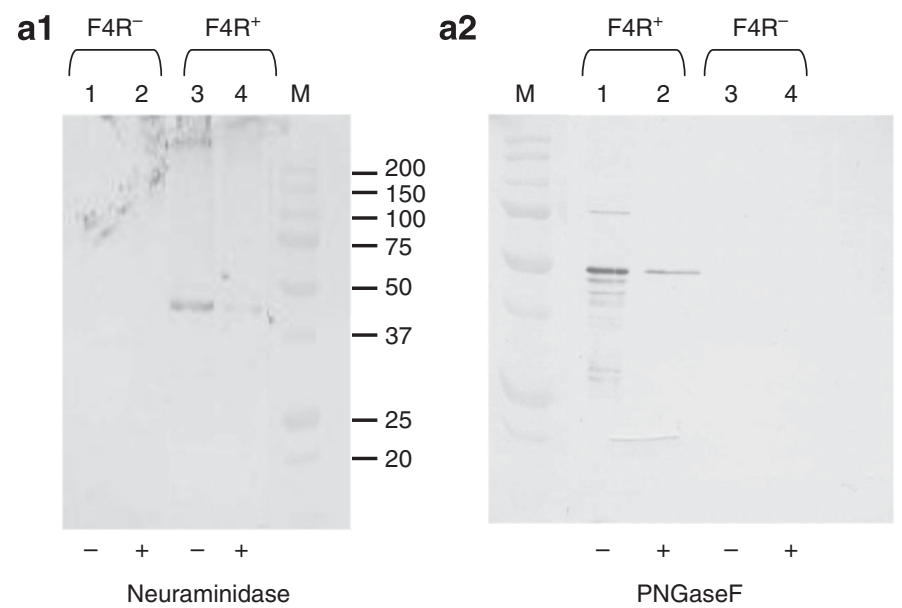

b1

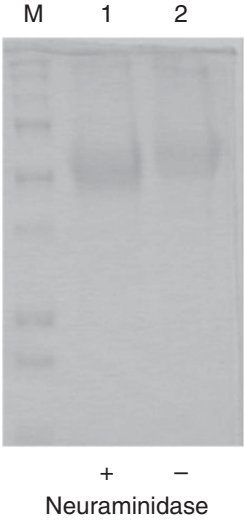

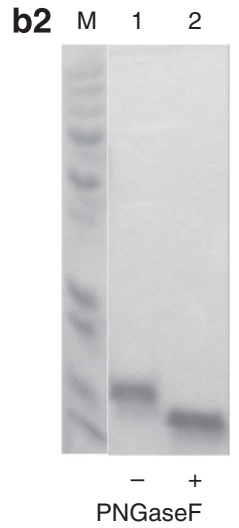
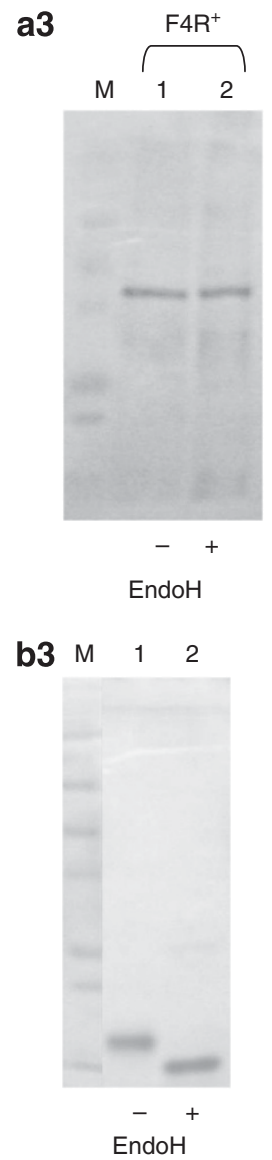

Figure 5 (a) Western blot analysis of the binding of F4ac fimbriae after removing sialic acids and $\mathrm{N}$-glycans. (a1) The brush border membrane vesicles (BBMVs) of F4 receptor (F4R) - (lanes 1 and 2) and F4R+ pigs (lanes 3 and 4) were treated with neuraminidase (lanes 2 and 4). Untreated samples were run on lanes 1 and 3. The positions of the molecular weight marker (M, kDa) are indicated. (a2) The BBMVs of F4R+ (lanes 1 and 2) and F4R - pigs (lanes 3 and 4) were treated with PNGaseF (lanes 2 and 4). Untreated samples were run on lanes 1 and 3. (a3) The BBMVs of an F4R + pig were treated with endoglycosidase $\mathrm{H}$ (EndoH; lane 2), an untreated sample was run on lane 1. (b) As a positive control, fetuin was treated with neuraminidase ((b1), lane 1) and RNaseB was treated with PNGaseF (b2, lane 2) or with EndoH (b3, lane 2), and a Coomassie staining was performed to observe if a gel shift occurred compared with the untreated samples (b1, lane 2; b2, lane 1; and b3, lane 1).

that interactions between sialic acid residues on pAPN and F4ac fimbriae are essential for binding.

Another important issue was whether pAPN has a role in endocytosis of F4ac, which could be an important factor in the reported ability of F4ac to transcytose small intestinal enterocytes and to induce a mucosal immune response. ${ }^{6,8}$ We recently demonstrated that F4ac fimbriae are internalized in the porcine epithelial cell line IPECJ2 via clathrin-mediated endocytosis. However, we were unable to detect APN expression on the surface of IPECJ2 cells using monoclonal or polyclonal APNspecific antibodies (unpublished data), suggesting that APN expression is below the detection limit using these antibodies or that other receptors are involved in endocytosis of F4 in this in vitro system. Therefore, we performed experiments with pAPN-transfected BHK-21 cells to evaluate the role of APN in endocytosis of $\mathrm{F} 4 \mathrm{ac}$ fimbriae. A role for APN in endocytosis was supported by the inhibitory effect of bestatin, an APN inhibitor, on endocytosis of F4 in pAPN-transfected BHK-21 cells. During several steps of ligand-induced endocytosis of cellular receptors, microtubules, actin, and clathrin are of critical importance. ${ }^{17-19}$ Experiments with chemical inhibitors and pAPN-transfected BHK-21 cells confirmed the importance of these structural proteins in pAPN-mediated internalization of F4ac. The importance of clathrin during the early phases of F4ac internalization was shown by inhibition of clathrin-coated pit invagination at the plasma membrane using amantadine- $\mathrm{HCl}$. In addition, inhibition of clathrin-coated vesicle budding using cytochala$\sin \mathrm{D}$ also resulted in a strong decrease in F4ac internalization. Furthermore, colocalization of vesicles containing F4ac and clathrin could be observed during F4 internalization. Similarly, endocytosis of gonococci-expressing galactose-terminating lipooligosaccharide that binds to the human asialoglycoprotein receptor occurs through clathrin-dependent receptor-mediated endocytosis. ${ }^{21}$ Other bacterial pathogens, such as Chlamydia species, ${ }^{22-24}$ Campylobacter jejuni, and Citrobacter freundii, ${ }^{25}$ some strains of enterohemorrhagic E. coli ${ }^{26}$ and Staphylococcus aureus ${ }^{27}$ have also been found to invade host cells by receptormediated endocytosis in a clathrin-dependent matter. 

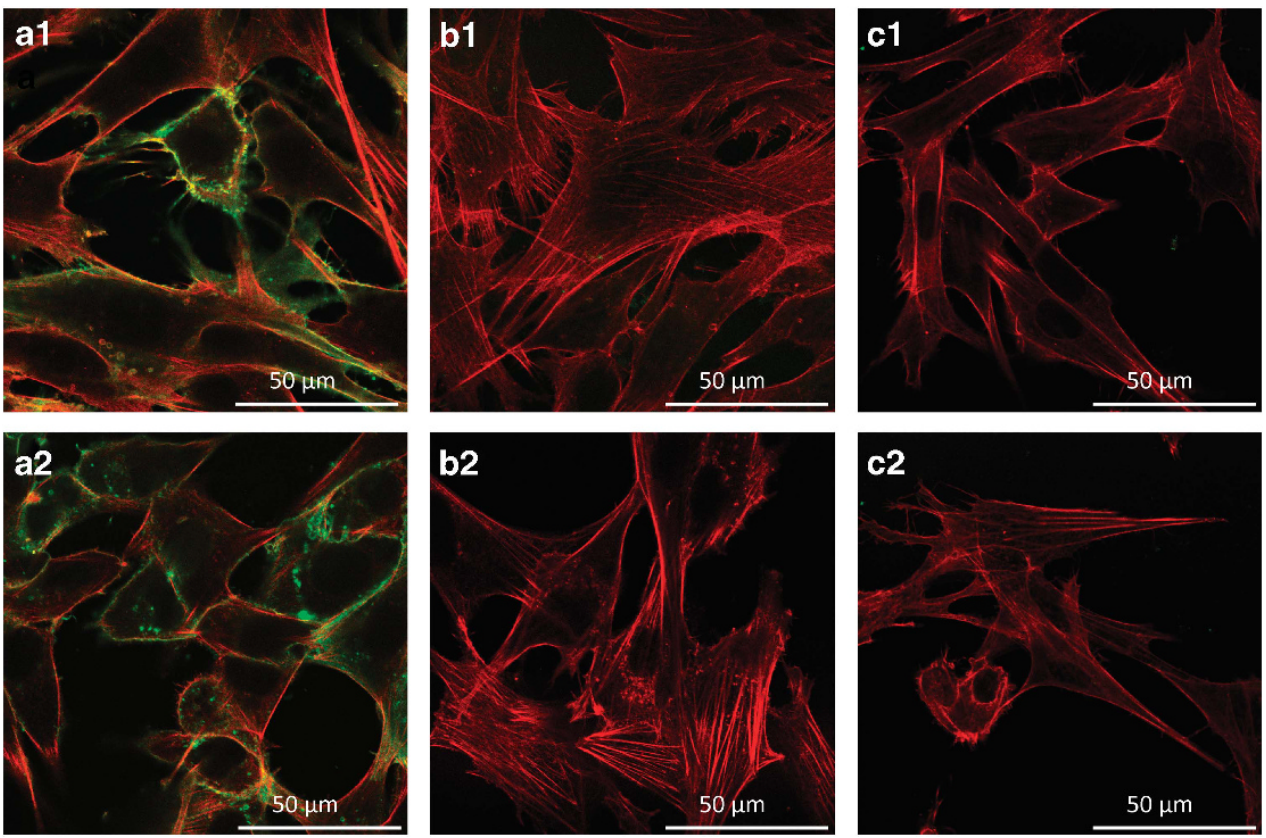

Figure 6 Endocytosis of aminopeptidase N (APN)-specific antibodies in vitro. Porcine (p)APN-transfected BHK-21 were incubated with anti-APN (a) or irrelevant rabbit serum (b) and untransfected BHK-21 cells were incubated with anti-APN (c) for $1 \mathrm{~h}$ at $4^{\circ} \mathrm{C}$ to allow binding but no internalization. Then, cells were shifted to $37^{\circ} \mathrm{C}$ to evaluate endocytosis. After 0 (a1, b1, and $\mathbf{c 1}$ ) and 20 min incubation (a2, b2, and c2), endocytosis was checked via confocal microscopy. Binding and/or uptake of anti-APN was assessed with anti-rabbit fluorescein isothiocyanate, and phalloidin-Texas Red was used to detect the actin cytoskeleton.
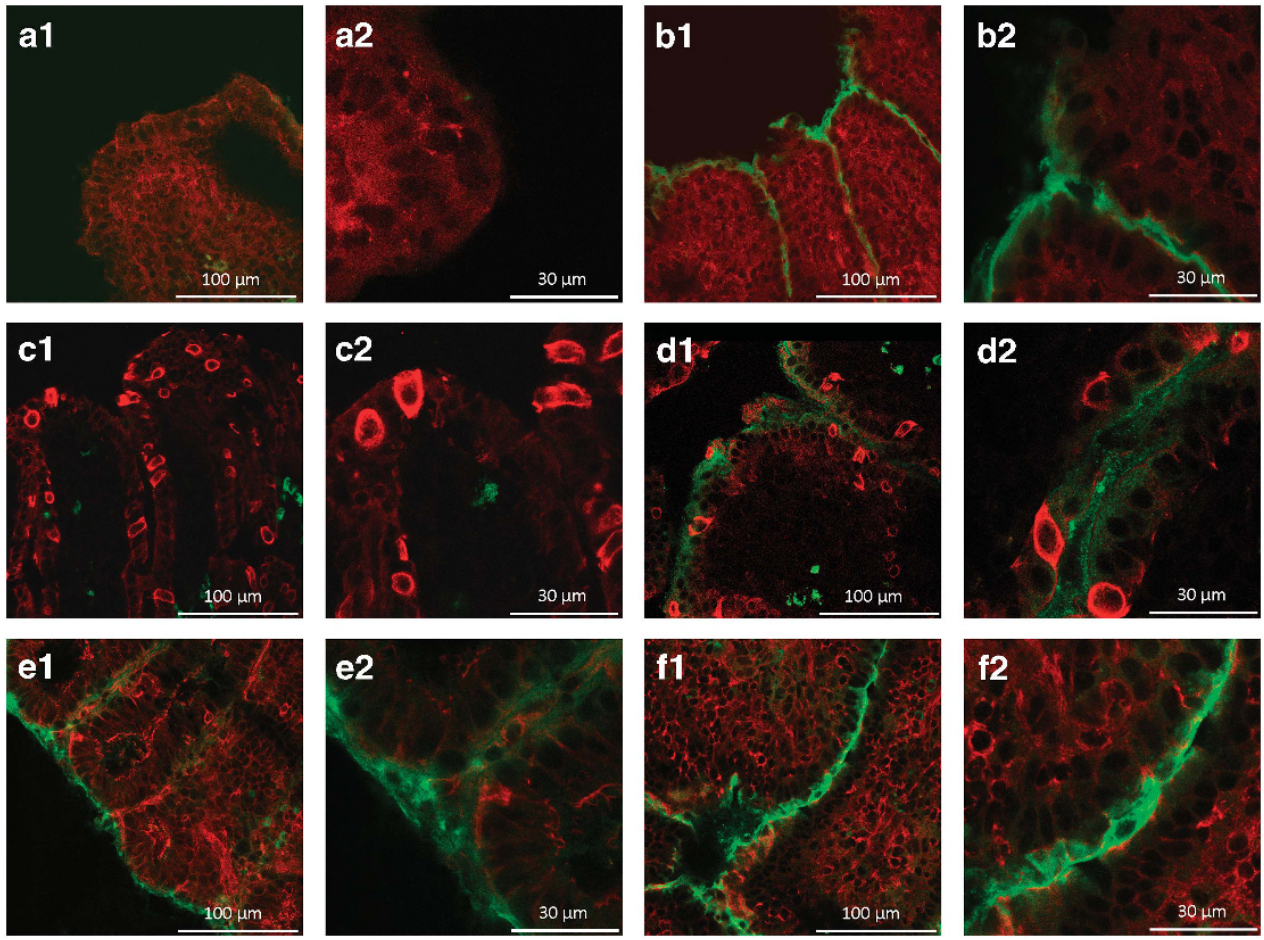

Figure 7 Confocal view of the jejunum of a pig after 5, 15, or 45 min incubation in vivo with irrelevant rabbit serum (a1, a2; c1, c2; e1, and e2, respectively) or anti-aminopeptidase N (APN) (b1, b2; d1 , d2; f1, and f2, respectively). Binding and/or uptake of anti-APN and the irrelevant rabbit serum were assessed with anti-rabbit fluorescein isothiocyanate. In $\mathbf{a}, \mathbf{b}, \mathbf{e}$, and $\mathbf{f}$, the actin cytoskeleton was detected with phalloidin-Texas Red, whereas in $\mathbf{c}$ and $\mathbf{d}$, anti-cytokeratin 18 was used to stain the enterocytes.

Oral administration of large doses of non-replicating antigens can induce a short-lived mucosal IgA response, ${ }^{6}$ but mostly results in a systemic state of immunological hyporesponsiveness, called oral tolerance. ${ }^{28,29}$ On the other hand, receptor-mediated uptake of orally administered antigens may result in the induction of an antigen-specific mucosal immune response. ${ }^{30}$ 

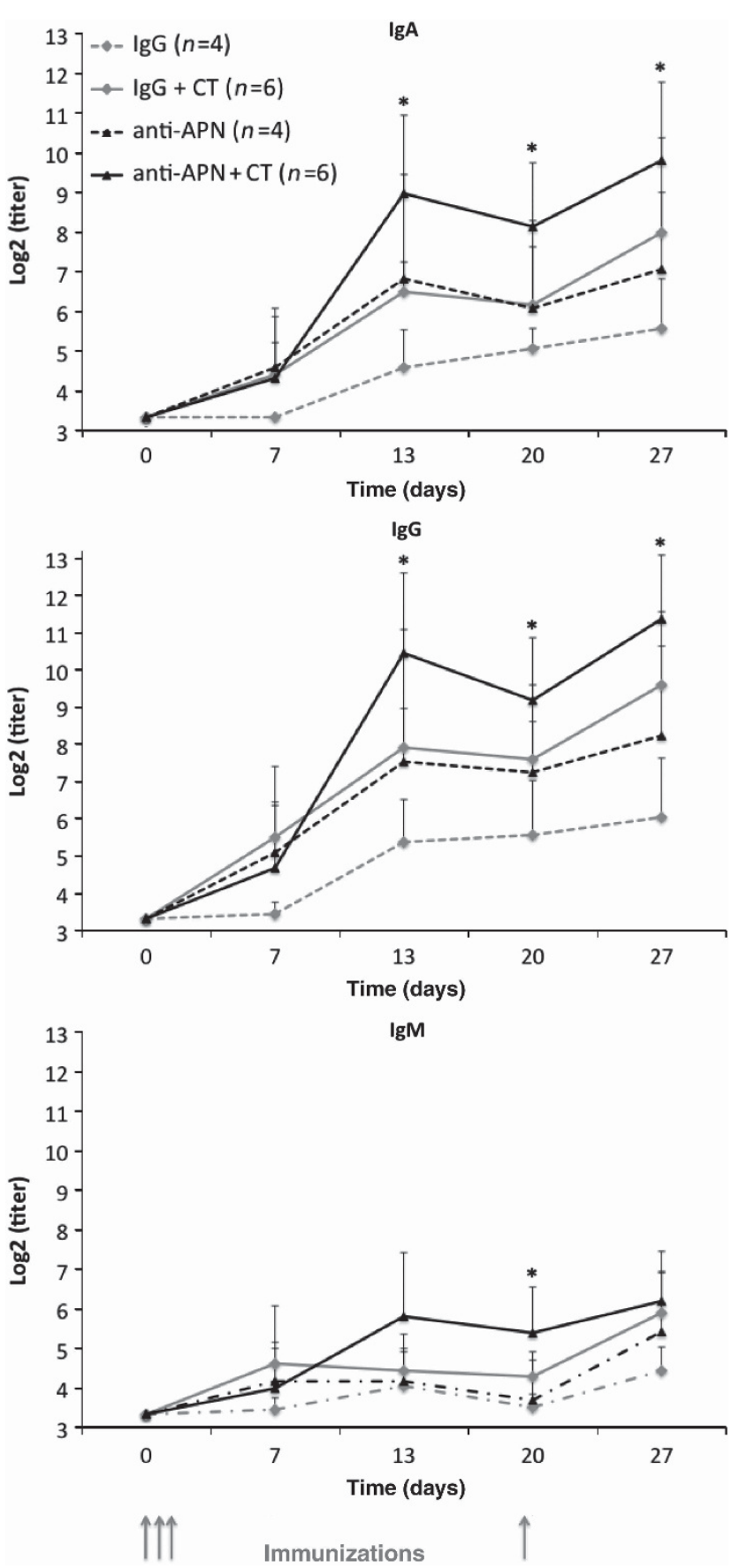

Figure 8 Kinetics of the rabbit immunoglobulin (Ig)G-specific serum $\lg A$, IgM, and $\lg G$ response. Pigs were orally immunized with polyclonal porcine aminopeptidase N (pAPN)-specific rabbit IgG (anti-APN; antiAPN group, $n=4)$, irrelevant rabbit IgG (IgG group, $n=4)$, anti-APN adjuvanted with cholera toxin (CT) (anti-APN + CT group, $n=6$ ), or irrelevant rabbit IgG adjuvanted with CT (IgG $+C T$ group, $n=6)$ on days $0,1,2$, and identically boosted on day 20 . Serum samples were taken weekly until day 7 after the boost. Results are presented as the mean \pm s.d. Significant differences between the anti-APN + CT group and the IgG group are indicated with asterisk.

F4 fimbriae represent one of the rare molecules that induce a strong mucosal immune response following oral administration. This immune response requires the presence of the F4R as oral immunization of $\mathrm{F} \mathrm{R}^{-}$piglets with $\mathrm{F} 4$ fimbriae does not result in the induction of an F4-specific mucosal immune response. ${ }^{6} \mathrm{~F} 4$ strongly adheres to the villous epithelium and the follicle-associated epithelium of the jejunum and ileum of F4R ${ }^{+}$ pigs and is endocytosed by villous enterocytes, follicle-associated enterocytes, and $\mathrm{M}$ cells. ${ }^{8}$ Intestinal mucin-type glycoprotein 1 and 2 have been identified as receptors for F4ac, ${ }^{9,10}$ but there are no indications that these would be involved in endocytosis and mucosal immunity against F4 fimbriae. Here, we demonstrate that pAPN serves as an F4acR and does lead to F4 internalization. An additional indication for the involvement of pAPN in the oral immunogenicity of F4 comes from our observation that antibodies against $\mathrm{APN}$, which also adhere to and are taken up by enterocytes, elicited a strong immune response. Even in the absence of an adjuvant, strong serum $\operatorname{IgA}, \operatorname{IgG}$, and IgM responses could be observed after primary immunization, indicating that APN may represent a promising target for oral delivery of antigens across the epithelial barrier. Although much weaker than observed with APN-specific antibodies, irrelevant rabbit antibodies also interacted with enterocytes and induced a weak serum antibody response. This might be explained by the fact that the neonatal receptor for IgG, FcRn, is expressed on porcine intestinal epithelium throughout lifetime and is in line with another study demonstrating that orally delivered bovine IgG to pigs was transferred into the blood supply. ${ }^{31}$ In conclusion, we identified APN as a novel F4 receptor. APN is expressed on the small intestinal brush border and is involved in the adhesion of F4ac ${ }^{+}$ETEC, to the intestinal epithelium. The interaction between F4 fimbriae and APN critically depends on the presence of sialic acid containing carbohydrate structures and binding of F4 fimbriae to APN results in clathrin-mediated endocytosis of the fimbriae. The fact that APN is present on the intestinal epithelium of many animal species, makes this molecule an interesting candidate for the selective targeting of vaccine antigens towards the mucosal epithelium.

\section{METHODS}

In vitro villous adhesion assay for F4acR characterization of the piglets. In order to determine the presence or absence of the F4acR on brush borders of small intestinal villous enterocytes, an in vitro villous adhesion assay was performed as described $^{6}$ on 13 pigs from 13 different sows and 13 different boars of 5 different pig farms in Northern Belgium. Adhesion of more than five bacteria per $250 \mu \mathrm{m}$ villous brush border length was noted as positive.

Purification of F4 fimbriae and labeling with fluorescein. F4 fimbriae were purified as described. ${ }^{6}$ The F4 was labeled with 5(6)-carboxyfluorescein- $N$-hydroxysuccinimide ester (FLUOS, $480 \mathrm{Da}$ ) using the fluorescein labeling kit (Roche Diagnostics GmbH, Mannheim, Germany). The molar reaction ratio F4: FLUOS used was 1:10. The remaining nonreacted FLUOS was blocked by adding $1 \mathrm{mM}$ glycin (incubation $1 \mathrm{~h}$ at $18^{\circ} \mathrm{C}$ ), which was subsequently removed by dialysis against phosphatebuffered saline (PBS). Before use, the binding of the FLUOS-labeled F4 fimbriae (F4-FluoS) to the F4R on villous brush border enterocytes was tested in vitro.

Enterocyte brush border membrane vesicle preparations. Small intestinal epithelial cells from the pig were isolated by the method of 
Lundqvist et al. ${ }^{32}$ The purity of the samples was analyzed by light microscopy, and we obtained consistently $\geq 85 \%$ enterocytes in our isolated cell populations. Subsequently, BBMVs were prepared from $\mathrm{F}_{4} \mathrm{R}^{+}$and $\mathrm{F} 4 \mathrm{R}^{-}$pigs by the method of Kessler et al. ${ }^{33}$ with a slight modification. Briefly, enterocytes were washed twice in PBS with $0.1 \mathrm{mM}$ phenylmethylsulfonyl fluoride and were resuspended in Tris- $\mathrm{HCl}$ buffer $(2 \mathrm{mM}, \mathrm{pH}$ 7.2) containing $50 \mathrm{mM}$ mannitol in a ratio of $3: 1(\mathrm{v} / \mathrm{v})$. Next, the cells were homogenized for 2 min with an Ultra Turrax (Janke \& Kunkel, IKA Labortechnik, Staufen, Germany) and placed on ice for $15 \mathrm{~min}$ after having adjusted $\mathrm{CaCl}_{2}$ to a final concentration of $10 \mathrm{mM}$. The homogenate was subsequently centrifuged at $27,000 \times g$ for $30 \mathrm{~min}$, the pellet suspended in Tris buffer ( $\mathrm{pH} 7.5)$ containing $50 \mathrm{mM}$ mannitol and $10 \mathrm{mM} 4-(2-$ hydroxyethyl)-1-piperazineethanesulfonic acid and centrifuged again. The pellet was resuspended in the same buffer and used for the study. The protein concentration of the obtained BBMV was determined using the bicinchoninic acid reaction with bovine serum albumin as a standard (ICN Biomedicals, Asse, Belgium).

Two-dimensional electrophoresis. For the first-dimension isoelectric focusing, $11 \mathrm{~cm}$ ReadyStrip Immobilized $\mathrm{pH}$ gradient Strips with $\mathrm{pH}$ gradient $4-7$ were used (Bio-Rad, Hercules, CA). BBMVs $(500 \mu \mathrm{g})$ were incorporated into the Immobilized $\mathrm{pH}$ gradient strips by in-gel rehydration in a total of $250 \mu \mathrm{l}$ rehydration solution (7 M urea, $2 \mathrm{M}$ thiourea, $2 \%$ w/v CHAPS, $2 \%$ carrier ampholytes, and a trace of bromophenol blue) for at least $6 \mathrm{~h}$. Strips were isoelectrically focussed on the Protean IEF System (Bio-Rad) at $18^{\circ} \mathrm{C}$, using $100 \mathrm{~V}$ for $30 \mathrm{~min}$ (linear ramping), $250 \mathrm{~V}$ for $30 \mathrm{~min}$ (linear ramping), 1,000 V for $30 \mathrm{~min}$ (linear ramping), rapid ramping to $8,000 \mathrm{~V}$ in $2 \mathrm{~h}$, and steady state at $8,000 \mathrm{~V}$ for $25,000 \mathrm{Vh}$. After isoelectric focussing, the strips were treated with equilibration solution (50 mM Tris- $\mathrm{HCl} \mathrm{pH} \mathrm{6.8,6} \mathrm{M} \mathrm{urea,} 20 \% \mathrm{v} / \mathrm{v}$ glycerol, and $2 \% \mathrm{w} / \mathrm{v}$ sodium dodecyl sulfate) supplemented with $1.5 \% \mathrm{w} / \mathrm{v}$ dithiothreitol for $15 \mathrm{~min}$ followed by $15 \mathrm{~min}$ in equilibration solution supplemented with $4 \% \mathrm{w} / \mathrm{v}$ iodoacetamide. The second-dimension sodium dodecyl sulfate-polyacrylamide gel electrophoresis was performed on a vertical electrophoresis system (Bio-Rad) using Laemmli 10\% resolving polyacrylamide gels and run in sets of 2 at $150 \mathrm{~V}$ for $30 \mathrm{~min}$ followed by $200 \mathrm{~V}$ until the bromophenol blue front reached the edge of the gel.

One of the gels was stained with Sypro Ruby (Molecular Probes, Eugene, OR, USA) for $3 \mathrm{~h}$. After staining, the gel was washed twice in $10 \%$ methanol, $7 \%$ acetic acid for 15 min to obtain low residual matrix background. A protein standard marker (MagicMark XP, Invitrogen, Merelbeke, Belgium) was loaded on each gel.

Immunoblotting. The remaining gel was used for immunoblotting. The proteins were transferred onto a nitrocellulose membrane by wet blotting using the Trans-Blot Cell (Bio-Rad) at a constant voltage of $50 \mathrm{~V}$ for $3 \mathrm{~h}$. Before blotting, both the polyacrylamide gel and nitrocellulose membrane were incubated in CAPS $1 \times(\mathrm{pH} 11)$ for at least $15 \mathrm{~min}$.

Ponceau S visualization was performed to check the blotting efficiency and to verify the two-dimensional pattern. This stained membrane was scanned, digitized, and used as a reference image of the most abundant proteins. The membrane was subsequently destained, blocked overnight at $4{ }^{\circ} \mathrm{C}$ with $5 \%$ nonfat dry milk and $0.3 \%$ Tween- 80 in PBS, and incubated for $1 \mathrm{~h}$ at room temperature with $2 \mu \mathrm{g} \mathrm{ml}^{-1} \mathrm{~F} 4$ fimbriae. Thereafter, the membrane was incubated with the F4-specific monoclonal antibody IMM- $01^{34}$ for $1 \mathrm{~h}$, rabbit anti-mouse horseradish peroxidase conjugate (Dako, Glostrup, Denmark) for $1 \mathrm{~h}$ (dilution 1:1,000), and ECL western blotting substrate (Pierce Biotechnology, Rockford, IL, USA) for $5 \mathrm{~min}$ to visualize F4 fimbriae-binding proteins. Between each step, the membrane was washed three times with $0.3 \%$ Tween-20 in PBS for 5 min.

In-gel digestion and peptide sample preparation. Protein spots were excised from the gel and digested in-gel with sequence grade modified trypsin (porcine; Promega, Madison, WI). Two washing steps were performed by adding $25 \mathrm{mM} \mathrm{NH}_{4} \mathrm{HCO}_{3}$ and $50 \%$ acetonitrile for $10 \mathrm{~min}$.
A volume of $10 \mathrm{mM}$ dithiothreitol in $25 \mathrm{mM} \mathrm{NH}_{4} \mathrm{HCO}_{3}$ sufficient to cover the gel pieces was added and the proteins were reduced for $10 \mathrm{~min}$ at $56^{\circ} \mathrm{C}$. After cooling to room temperature for $20 \mathrm{~min}$, the dithiothreitol solution was replaced with the same volume of $100 \mathrm{mM}$ iodoacetamide in $25 \mathrm{mM} \mathrm{NH}_{4} \mathrm{HCO}_{3}$. After 45-min incubation at ambient temperature in the dark with occasional shaking, the gel pieces were washed once with $25 \mathrm{mM} \mathrm{NH}_{4} \mathrm{HCO}_{3}$ and $50 \%$ acetonitrile for $10 \mathrm{~min}$, dehydrated by addition of acetonitrile, and completely dried in a vacuum centrifuge. The gel pieces were digested for $30 \mathrm{~min}$ in $10 \mathrm{ng} \mathrm{Hl}^{-1}$ trypsin on ice. After incubation overnight at $37^{\circ} \mathrm{C}$, peptides were extracted first with $50 \%$ acetonitrile and subsequently with $100 \%$ acetonitrile (30 min for each change). The liquid phase was pooled and completely dried in a vacuum centrifuge.

Identification by electrospray ionization mass spectrometry. Dried peptide mixtures were solubilized in $10 \mu \mathrm{l} 0.1 \%$ formic acid and injected on an on-line nano LC system using column switching (LC Packings, Sunnyvale, CA, USA) coupled to a Q-TOF Ultima mass spectrometer (Waters, Milford, MA) fitted with an orthogonal Z-spray. The data were acquired using automatic function switching software from MassLynx 4.0 (Waters). The fragmentation spectra, resulting from tandem mass spectrometry, were processed by ProteinLynx Global Server v2.2.5 software (Waters). The resulting pkl files were aligned against the Swiss-prot database using the MASCOT search engine (http://www.matrixscience.com).

Production of polyclonal rabbit anti-APN serum. A rabbit was intramuscularly immunized with $500 \mu \mathrm{g}$ pAPN (leucine aminopeptidase isolated from porcine kidney microsomes, Sigma-Aldrich, Bornem, Belgium) mixed with incomplete Freund's adjuvant in a 1:1 ratio at 3 -weeks interval. Two weeks after the second immunization, serum was collected upon analysis of the antibody titer in enzyme-linked immunosorbent assay (ELISA).

Cell line and culture conditions. The BHK-21 and pAPN-transfected BHK-21 cells were kindly gifted by Dr Laude of the Unit of Virology and Molecular Immunology of the INRA in France. The BHK-21 cells were cultured in Dulbecco's modified Eagle's medium with $5 \%$ fetal calf serum, $1 \%$ L-glutamine, $1 \%$ penicillin-streptomycin, $1 \%$ sodiumpyruvate (Gibco BRL, Life Technologies, Paisley, Scotland), and 1\% nonessential amino acids (Gibco BRL). The pAPN-transfected BHK-21 cells were grown in the same medium supplemented with $1.5 \mathrm{mg} \mathrm{ml}^{-1}$ Geneticin ${ }^{\circ}$ G418 (Sigma-Aldrich).

Glycosidase treatment. To remove sialic acids, $2 \mathrm{mg} \mathrm{ml}^{-1} \mathrm{BBMV}$ from $\mathrm{F}_{4} \mathrm{R}^{+}$pigs were incubated with soluble neuraminidase from $A$. urefaciens (Calbiochem, San Diego, CA; specific for $\alpha 2-3,6,8,9$-linked sialic acid) for $3 \mathrm{~h}$ at $37^{\circ} \mathrm{C}$ according to the manufacturer's instructions. Fetuin, a sialic acid-containing protein, was used as a positive control and the buffer, in which the neuraminidase was provided, was used as a negative control. BBMVs from $\mathrm{F} 4 \mathrm{R}+$ pigs were treated with $N$-glycosidase $\mathrm{F}$ (NEB, Beverly, MA) or with endoglycosidase $\mathrm{H}$ (NEB) according to the manufacturer's instructions to remove all $N$-glycans or $N$-glycans of the high-mannose type, respectively. RNase B was used as a positive control and the buffer, in which the enzyme was provided, was used as a negative control. BBMVs from $\mathrm{F}_{4} \mathrm{R}^{+}$pigs were treated with variable concentrations of $\mathrm{NaIO}_{4}$ (Sigma-Aldrich) in $50 \mathrm{mM}$ sodiumacetate, $\mathrm{pH} 4.5$, at $37^{\circ} \mathrm{C}$ in the dark. Reactions were stopped by the addition of ethylene glycol to a final concentration of $20 \mathrm{mM}$. BBMVs from $\mathrm{F}_{4} \mathrm{R}^{-}$pigs were treated with the same glycosidases and were used as a negative control.

Endocytosis assay. The BHK-21 and pAPN-transfected BHK-21 cells were incubated with $25 \mu \mathrm{g}$ F4-FLUOS or an optimal dilution of the pAPN-specific polyclonal serum or irrelevant rabbit serum for $1 \mathrm{~h}$ at $4^{\circ} \mathrm{C}$ to allow attachment, but no internalization. Cells were then washed with PBS supplemented with $0.1 \mathrm{mM} \mathrm{CaCl}_{2}$ and $1 \mathrm{mM} \mathrm{MgCl}_{2}\left(\mathrm{PBS}^{+}\right)$to remove unbound ligands and shifted to $37^{\circ} \mathrm{C}$ to start endocytosis. After 
Table 2 Inhibitors used in the study

\begin{tabular}{|c|c|c|}
\hline Inhibitor & Function & Concentrations $\mu \mathrm{m}$ \\
\hline Amantadine & $\begin{array}{l}\text { Interferes with clathrin- } \\
\text { coated-pit invagination } \\
\text { at the plasma } \\
\text { membrane }\end{array}$ & $0-500$ \\
\hline $\begin{array}{l}\text { Dynamin } \\
\text { inhibitory } \\
\text { peptide }\end{array}$ & $\begin{array}{l}\text { Interferes with } \\
\text { clathrin- and caveolae } \\
\text {-mediated endocytosis } \\
\text { and phagocytosis }\end{array}$ & $0-50$ \\
\hline Latrunculin B & $\begin{array}{l}\text { Disrupts actin polym- } \\
\text { erization }\end{array}$ & $0-50$ \\
\hline Nystatin & $\begin{array}{l}\text { Interferes with caveo- } \\
\text { lae-mediated endo- } \\
\text { cytosis }\end{array}$ & $0-100$ \\
\hline Cytochalasin D & $\begin{array}{l}\text { Inhibits G-actin poly- } \\
\text { merization to F-actin } \\
\text { Inhibits budding of } \\
\text { clathrin-coated vesicles }\end{array}$ & $0-100$ \\
\hline Bestatin & $\begin{array}{l}\text { Inhibits enzymatic } \\
\text { activity of amino- } \\
\text { peptisase N }\end{array}$ & $0-50$ \\
\hline
\end{tabular}

0 and 20 (anti-APN) or 30 (F4-FLUOS) minutes incubation, cells were fixed with $3 \%$ paraformaldehyde, permeabilized with $0.1 \%$ Triton X-100, and stained with phalloidin-Texas Red (Molecular Probes) and/or goat anti-rabbit fluorescein isothiocyanate (Sigma-Aldrich) in $\mathrm{PBS}^{+}$for $1 \mathrm{~h}$ at $37^{\circ} \mathrm{C}$. Confocal images were acquired with a Leica SP5 AOBS confocal microscope (Leica Microsystems, Groot-Bijgaarden, Belgium).

To analyze the effect of different endocytosis inhibitors and the APN inhibitor bestatin, the cells were incubated with different concentrations of each inhibitor (Table 2). Inhibitors were added $30 \mathrm{~min}$ before the incubation with F4-FLUOS. Cells were then fixed with 3\% paraformaldehyde at the indicated times. For each concentration of the chemical inhibitors, the viability of the cells was analyzed after the addition of $10 \mu \mathrm{g}$ propidium iodide (Molecular Probes) by flow cytometry. The number of vesicles internalized by the cells was counted using confocal microscopy as described above.

Colocalization of clathrin. The BHK-21 and pAPN-transfected BHK-21 cells were incubated with $25 \mu \mathrm{g}$ F4-FLUOS at $37^{\circ} \mathrm{C}$ to allow internalization. After $30 \mathrm{~min}$, cells were washed with $\mathrm{PBS}^{+}$and fixed with $3 \%$ paraformaldehyde, permeabilized with $0.1 \%$ Triton X-100, and stained with 1:30 mouse anti-clathrin heavy chain IgM antibodies (clone CHC 5.9, ICN Biomedicals) in $\mathrm{PBS}^{+}$for $1 \mathrm{~h}$ at $37^{\circ} \mathrm{C}$. Later, cells were washed three times with $\mathrm{PBS}^{+}$and incubated with a 1:100 dilution of rat anti-mouse IgM Texas Red (Molecular Probes) for $1 \mathrm{~h}$ at $37^{\circ} \mathrm{C}$. Finally, cells were washed with $\mathrm{PBS}^{+}$, mounted, and analyzed by confocal microscopy.

In vivo endocytosis of polyclonal anti-APN. Two- to six-week-old pigs (Belgian Landrace) were fasted overnight and sedated by intramuscular injection with a mixture of $0.5 \mathrm{mg} \mathrm{kg}^{-1}$ midazolam, $0.1 \mathrm{mg} \mathrm{kg}^{-1}$ morfine, and $5-10 \mathrm{mg} \mathrm{kg}^{-1}$ ketamine. After $15 \mathrm{~min}$, the pigs were anesthesized by an intravenous injection of $2 \mathrm{mg} \mathrm{kg}^{-1}$ propofol. The pigs were intubated and anesthesia was maintained by a mixture of isoflurane and oxygen. Following laparatomy, $5-\mathrm{cm}$-long loops were created in the jejunal lamina propria as described previously. ${ }^{35}$ The loops were separated by an interloop segment of at least $5 \mathrm{~cm}$. Care was taken to minimize surgical trauma and to maintain an adequate blood supply to the ligated segments. Four loops were created in the first pig and two loops in the second pig. In both pigs, polyclonal anti-APN or irrelevant rabbit serum $1 / 20$ diluted in $5 \mathrm{ml}$ PBS was injected into the lumen of one loop, whereafter the loops were placed back into the abdominal cavity. After 10 min the additional loops of the first pig were injected with either polyclonal anti-APN or irrelevant rabbit serum, and $5 \mathrm{~min}$ later this pig was euthanized by an overdose of pentobarbital $\left(24 \mathrm{mg} \mathrm{kg}^{-1}\right)$. The other pig was kept under anesthesia for $45 \mathrm{~min}$ before being euthanized.

Immunohistochemistry. Immediately after euthanasia, the loops were excised and flushed with cold PBS, embedded in $2 \%(\mathrm{w} / \mathrm{v})$ methocel (Fluka, Bornem, Belgium) in water, snapfrozen in liquid nitrogen, and stored at $-80^{\circ} \mathrm{C}$ before use. Approximately $5-\mu \mathrm{m}$-thick cryosections were cut and mounted on 3-aminopropyl-triethoxysilane (Sigma-Aldrich)coated glass slides. After drying for $4 \mathrm{~h}$ at $60^{\circ} \mathrm{C}$, the sections were fixed in acetone for $10 \mathrm{~min}$ at $-20^{\circ} \mathrm{C}$ and stored at $-80^{\circ} \mathrm{C}$. When needed, the cryosections were air-dried during $1 \mathrm{~h}$, washed for $5 \mathrm{~min}$ in PBS and incubated with $10 \%$ goat serum in PBS for $30 \mathrm{~min}$ at $37^{\circ} \mathrm{C}$ in a humidity chamber. Subsequently, the sections were incubated for $1 \mathrm{~h}$ at $37^{\circ} \mathrm{C}$ with goat anti-rabbit fluorescein isothiocyanate (Sigma-Aldrich) and Phalloidin-Texas Red (Molecular Probes) or with goat anti-rabbit fluorescein isothiocyanate and anti-cytokeratin peptide-18 (Sigma-Aldrich) in the humidity chamber, followed by a 1-h incubation with Texas Red$\mathrm{X}$-labeled goat anti-mouse IgG (Molecular Probes). Cytokeratin-18 is exclusively present in epithelial cells and stains the enterocytes weakly and goblet cells intensely, whereas phalloidin stains the F-actin filaments present in every cell. The sections were washed twice for $5 \mathrm{~min}$ in PBS before mounting in glycerol containing $0.223 \mathrm{M}$ 1,4-diazobicyclo-(2,2,2)octane (Sigma-Aldrich) to counter photobleaching.

Oral immunization of pigs with polyclonal anti-APN. IgG antibodies were purified from the $\mathrm{pAPN}$-specific rabbit serum and from an irrelevant rabbit serum (negative control) with HiTrap Protein A columns (GE Healthcare, Zeist, The Netherlands) according to the manufacturer's protocol. Twenty six-week-old pigs were given orally $20 \mathrm{mg}$ rabeprazolum (Pariet, Janssen-Cilag, Berchem, Belgium) on three subsequent days to block the gastric $\mathrm{HCl}$ production and again 18 days later. Twentyfour hours following each rabeprazolum ingestion $(0,1,2$, and 20 days dppi), the pigs were orally immunized with $1 \mathrm{mg}$ of purified anti-APN (anti-APN group, $n=4), 1 \mathrm{mg}$ of purified anti-APN $+50 \mu \mathrm{g}$ (CT anti$\mathrm{APN}+\mathrm{CT}$ group, $n=6$ ), or as controls $1 \mathrm{mg}$ IgG purified from irrelevant rabbit serum (IgG group, $n=4$ ) or $1 \mathrm{mg}$ IgG purified from irrelevant rabbit serum $+50 \mu \mathrm{g}$ CT (IgG + CT group, $n=6)$ in $10 \mathrm{ml} \mathrm{PBS}$. Each animal was deprived of food and water from $3 \mathrm{~h}$ before till $2 \mathrm{~h}$ after gastric $\mathrm{pH}$ neutralization or immunization.

Serum samples were taken weekly and treated as described. The presence of rabbit IgG-specific antibodies was analyzed by ELISA. Hereto, the wells of a 96-well microtiter plate (NUNC, Maxisorb Immuno Plates, Roskilde, Denmark) were coated with $1 \mu \mathrm{g} \mathrm{ml}^{-1}$ of rabbit IgG in PBS. After $2-\mathrm{h}$ incubation at $37^{\circ} \mathrm{C}$, the remaining binding sites were blocked overnight at $4^{\circ} \mathrm{C}$ with PBS supplemented with $0.2 \%$ Tween 80 (Merck Eurolab, Leuven, Belgium). Next, twofold dilutions of the sera in ELISA dilution buffer (PBS, pH 7.4 + 0.2\% Tween $20+3 \%$ bovine serum albumin), starting at a dilution of $1 / 10$, were added and plates were incubated for $1 \mathrm{~h}$ at $37^{\circ} \mathrm{C}$. Subsequently, plates were incubated with anti-swine IgM-, IgA-, or IgGspecific monoclonal antibody $\left(28.4 .1,27.8 .1\right.$, and 23.3 .1 b, respectively $\left.{ }^{36}\right)$ in ELISA dilution buffer for $1 \mathrm{~h}$ at $37^{\circ} \mathrm{C}$, followed by rabbit anti-mouse horseradish peroxidase conjugate (Dako) optimally diluted in ELISA dilution buffer supplemented with $5 \%$ rabbit serum, for $1 \mathrm{~h}$ at $37^{\circ} \mathrm{C}$. Finally, ABTS (Roche Diagnostics, Brussels, Belgium) containing $\mathrm{H}_{2} \mathrm{O}_{2}$ was added, plates were incubated for $30 \mathrm{~min}$ at $37^{\circ} \mathrm{C}$, and optical density was measured spectrophotometrically at $405 \mathrm{~nm}$ (optical density ${ }_{405}$ ). Between each incubation step, the plates were washed thrice with ELISA washing buffer (PBS, pH 7.4+2\% Tween 20). Cutoff values were obtained by increasing the mean optical density ${ }_{405}$ of all sera (dilution $1 / 10$ ) on day 0 dppi with three times its s.d., resulting in cutoff values of $0.22,0.37$, and 0.52 for IgA, IgG, and IgM, respectively. The antibody titer was the inverse of the highest dilution that still had an optical density ${ }_{405}$ higher than the calculated cutoff values. Results were analyzed statistically with 
SPSS 16.0 for Windows (IBM, New York, NY) using General Linear Model (repeated measures analysis of variance) with the Bonferoni adjustment for multiple comparisons.

\section{ACKNOWLEDGMENTS}

This work was supported by the Research Fund of the Ghent University (BOF) and the FWO-Flanders, Hercules Foundation, and IWT Flanders.

\section{DISCLOSURE}

The authors declared no conflict of interest.

(C) 2012 Society for Mucosal Immunology

\section{REFERENCES}

1. Clarke, S.C. Diarrheagenic Escherichia coli - an emerging problem? Diagn. Microbiol. Infect. Dis. 41, 93-98 (2001).

2. Ratchtrachenchai, O.A., Subpasu, S., Hayashi, H. \& Ba-Thein, W. Prevalence of childhood diarrhea-associated Escherichia coli in Thailand. J. Med. Microbiol. 53, 237-243 (2004).

3. Moon, H.W., Hoffman, L.J., Cornick, N.A., Booher, S.B. \& Bosworth, B.T. Prevalences of some virulence genes among Escherichia coli isolates from swine presented to a diagnostic laboratory in lowa. J. Vet. Diagn. Invest. 11, 557-560 (1999).

4. Conzelman, C. Schwein 99: Ferkelverluste. Suisseporcs -Inf. 10, 22-3 (2000).

5. Gibbons, R.A., Sellwood, R., Burrows, M. \& Hunter, P.A. Inheritance of resistance to neonatal $E$. coli diarrhea in the pig: examination of the genetic system. Theor. Appl. Gen. 51, 65-70 (1977).

6. Van den Broeck, W., Cox, E. \& Goddeeris, B.M. Receptor-specific binding of purified F4 to isolated villi. Vet. Microbiol. 68, 255-263 (1999).

7. Verdonck, F., De Hauwere, V., Bouckaert, J., Goddeeris, B.M. \& Cox, E. Fimbriae of enterotoxigenic Escherichia coli function as a mucosal carrier for a coupled heterologous antigen. J. Control. Release 104, 243-258 (2005).

8. Snoeck, V. et al. Transcytosis of F4 fimbriae by villous and dome epithelia in F4-receptor positive pigs supports importance of receptor-dependent endocytosis in oral immunization strategies. Vet. Immunol. Immunopathol. 124, 29-40 (2008).

9. Francis, D.H., Grange, P.A., Zeman, D.H., Baker, D.R., Sun, R. \& Erickson, A.K. Expression of mucin-type glycoprotein K88 receptors strongly correlates with piglet susceptibility to K88(+) enterotoxigenic Escherichia coli, but adhesion of this bacterium to brush borders does not. Infect. Immun. 66, 4050-4055 (1998).

10. Erickson, A.K., Willgohs, J.A., McFarland, S.Y., Benfield, D.A. \& Francis, D.H. Identification of two porcine brush border glycoproteins that bind the K88ac adhesion of Escherichia coli and correlation of these binding glycoproteins with the adhesive phenotype. Infect. Immun. 60, 983-988 (1992).

11. Olsen, J. et al. Complete amino acid sequence of human intestinal aminopeptidase $\mathrm{N}$ as deduced from cloned cDNA. FEBS Lett. 238, 307-314 (1988).

12. Delmas, B., Gelfi, J., Kut, E., Sjöström, H., Noren, O. \& Laude, H. Determinants essential for the transmissible gastroenteritis virus-receptor interaction reside within a domain of aminopeptidase- $\mathrm{N}$ that is distinct from the enzymatic site. J. Virol. 68, 5216-5224 (1994).

13. Delmas, B. et al. Aminopeptidase $\mathrm{N}$ is a major receptor for the enteropathogenic coronavirus TGEV. Nature 357, 417-419 (1992).

14. Yeager, C.L. et al. Human aminopeptidase $\mathrm{N}$ is a receptor for human coronavirus 229E. Nature 357, 420-422 (1992).

15. Tresnan, D.B., Levis, R. \& Holmes, K.V. Feline aminopeptidase N serves as a receptor for feline, canine, porcine, and human coronaviruses in serogroup I. J. Virol. 70, 8669-8674 (1996).
16. Krempl, C., Schultze, B., Laude, H. \& Herrler, G. Point mutations in the S protein connect the sialic acid binding activity with the enteropathogenicity of transmissible gastroenteritis coronavirus. J. Virol. 71, 3285-3287 (1997).

17. Goldstein, J.L., Brown, M.S., Anderson, R.G., Russell, D.W. \& Schneider, W.J. Receptor-mediated endocytosis: concepts emerging from the LDL receptor system. Annu. Rev. Cell. Biol 1, 1-39 (1985).

18. Hirst, J. \& Robinson, M.S. Clathrin and adaptors. Biochem. Biophys. Acta. 1404, 173-193 (1998).

19. Merrifield, C.J. et al. Endocytotic vesicles move at the tips of actin tails in cultured mast cells. Nat. Cell Biol. 1, 72-74 (1990).

20. Brodsky, F.M., Chen, C.Y., Knuehl, C., Towler, M.C. \& Wakeham, D.E. Biological basket weaving: formation and function of clathrin-coated vesicles. Annu. Rev. Cell Dev. Biol. 17, 517-568 (2001).

21. Porat, N., Apicella, M.A. \& Blake, M.S. Neisseria gonorrhoeae utilizes and enhances the biosynthesis of the asialoglycoprotein receptor expressed on the surface of the hepatic HepG2 cell line. Infect. Immun. 63, 14981506 (1995).

22. Söderlund, G. \& Kihlström, E. Effect of methylamine and monodansylcadaverine on the susceptibility of McCoy cells to Chlamydia trachomatis infection. Infect. Immun. 40, 534-541 (1983).

23. Hodinka, R.L. \& Wyrick, P.B. Ultrastructural study of mode of entry of Chlamydia psittaci into L-929 cells. Infect. Immun. 54, 855-863 (1986).

24. Wyrick, P.B. et al. Entry of genital Chlamydia trachomatis into polarized human epithelial cells. Infect. Immun. 57, 2378-2389 (1989).

25. Oelschlaeger, T.A., Guerry, P. \& Kopecko, D.J. Unusual microtubuledependent endocytosis mechanisms triggered by Campylobacter jejuni and Citrobacter freundii. Proc. Natl. Acad. Sci. USA 90, 6884-6888 (1993).

26. Oelschlaeger, T.A., Barret, T.J. \& Kopecko, D.J. Some structures and processes of human epithelial cells involved in uptake of enterohemorrhagic Escherichia coli O157:H7 strains. Infect. Immun. 62, 5142-5150 (1994).

27. Ellington, J.K., Reilly, S.S., Ramp, W.K., Smeltzer, M.S., Kellam, J.F. \& Hudson, M.C. Mechanisms of Staphylococcus aureus invasion of cultured osteoblasts. Microb. Pathog. 26, 317-323 (1999).

28. Stokes, C.R. \& Bailey, M. The porcine gastrointestinal lamina propria: an appropriate target for mucosal immunisation? J. Biotechnol. 83, 51-55 (2000).

29. Garside, P. \& Mowat, A.M. Oral tolerance. Semin. Immunol. 13, 177-185 (2001).

30. De Aizpurua, H.J. \& Russell Jones, G.J. Oral vaccination-identification of classes of proteins that provoke an immune response upon oral feeding. J. Exp. Med. 176, 440-451 (1988).

31. Stirling, C.M.A. et al. Characterization of the porcine neonatal FC receptor - potential use for trans-epithelial protein delivery. Immunology 114, 542-553 (2005).

32. Lundqvist, C., Hammarström, M.L., Athlin, L. \& Hammarström, S. Isolation of functionally active intraepithelial lymphocytes and enterocytes from human small and large intestine. J. Immunol. Methods 152, 253-263 (1992).

33. Kessler, M., Acuto, O., Storelli, C., Murer, H., Müller, M. \& Semenza, G. A modified procedure for the rapid preparation of efficiently transporting vesicles from small intestinal brush border membranes. Biochem. Biophys. Acta. 506, 136-154 (1978).

34. Van der Stede, Y., Cox, E. \& Goddeeris, B.M. Antigen dose modulates the immunoglobulin isotype responses of pigs against intramuscularly administered F4-fimbriae. Vet. Immunol. Immunopathol. 88, 209 (2002).

35. Moon, H.W., Sorensen, D.K. \& Sautter, J.H Escherichia coli infection of the ligated intestinal loop of the newborn pig. Am. J. Vet. Res. 27, 1317-1325 (1966).

36. Van Zaane, D. \& Hulst, M.M. Monoclonal antibodies against porcine immunoglobulin isotypes. Vet. Immunol. Immunopathol. 16, 23-36 (1987). 